\title{
Measuring Financial Market Stress
}

Kevin L. Kliesen, Economist

Douglas C. Smith, Senior Research Associate

$\mathrm{T}$ he recent public debate over financial regulatory reform has been heated and involved. Some have argued that we need an agency charged with monitoring financial market developments that are deemed to pose a risk to the entire financial system-or to firms deemed systemically important. Presumably, one of the requirements of such a systemic risk regulator would be to measure financial market "stress."

There are many ways to measure financial market stress. One is to look at an interest rate spread designed to measure default risk, such as the difference between yields on a "risky" asset (e.g., corporate bonds) and a "risk-free" asset (e.g., U.S. Treasury securities). However, financial stress can also arise in other dimensions. One type of risk prominent in the recent financial crisis was the inability of many financial institutions to secure funding to finance their short-term liabilities, such as repurchase agreements (repos). This type of risk is known as "liquidity risk." 1

To overcome a potential problem of focusing solely on one indicator at the expense of others, some economists have combined several indicators designed to measure financial market stress into one summary variable, like an index number. A recent example of such an index is the Kansas City Financial Stress Index (KCFSI), ${ }^{2}$ which is a measure constructed by the Federal Reserve Bank of Kansas City that uses 11 financial market variables. However, one potential limitation of the KCFSI is its use of monthly data. Significant developments in the financial markets often occur much more frequently (e.g., the difficulties associated with Bear Stearns and Lehman Brothers), so a more "realtime" index might be better. The trade-off for a higherfrequency index, of course, is greater volatility, and thus, perhaps, noise.

The charts on the next page plot a financial stress index constructed by the Federal Reserve Bank of St. Louis (STLFSI); it is based on 18 weekly data series. There are seven interest rate series, six yield spreads, and five other financial series that begin in late 1993. Principal components analysis is used to construct the STLFSI, which is similar to the construction for the KCFSI. ${ }^{3}$

\section{Although the STLFSI suggests the level of financial stress in the markets has declined significantly since September 2008, the stress level remains modestly higher than average.}

To gauge whether the STLFSI can be used to measure the degree of financial stress in the market, the chart plots vertical lines at three key events over the past several years. In the first chart, the lines are marked at (i) the Russian debt moratorium in August 1998 that helped to precipitate the Asian financial crisis and the associated collapse in the U.S. hedge fund Long-Term Capital Management; (ii) the decision by the Paris-based BNP Paribas banking group in August 2007 to suspend redemptions from three of its mutual funds with significant holdings of U.S. asset-backed securities; and (iii) the bankruptcy of the investment bank Lehman Brothers in September 2008. The second chart adds other key events during the financial crisis. In each instance, the STLFSI seemed to accurately capture the subsequent turmoil and financial stress. In one sense, the STLFSI and the KCFSI can be thought of as coincident indexes rather than as leading indexes-that is, they are designed to measure developments as they occur. In another sense, however, they have leading indicator properties because rising levels of financial stress, as recently seen, can portend economic turmoil and disruption.

Although the STLFSI suggests the level of financial stress in the markets has declined significantly since September 2008, the stress level still remains modestly higher than average.

\footnotetext{
${ }^{1}$ See Sengupta, Rajdeep and Tam, Yu Man. "The LIBOR-OIS Spread as a Summary Indicator." Federal Reserve Bank of St. Louis Monetary Trends, November 2008;

http://research.stlouisfed.org/publications/mt/20081101/cover.pdf.

${ }^{2}$ See the KSFSI at www.kansascityfed.org/home/subwebnav.cfm?level=3\&the $\underline{\mathrm{ID}=11150 \& \text { SubWeb }=10681 \text {. }}$.

${ }^{3}$ See the online appendix at

http://research.stlouisfed.org/publications/net/NETJan2010Appendix.pdf for more details about the construction of the STLFSI, the data series used, and an interpretation of the scaling of the vertical axis.
} 


\section{St. Louis Financial Stress Index}

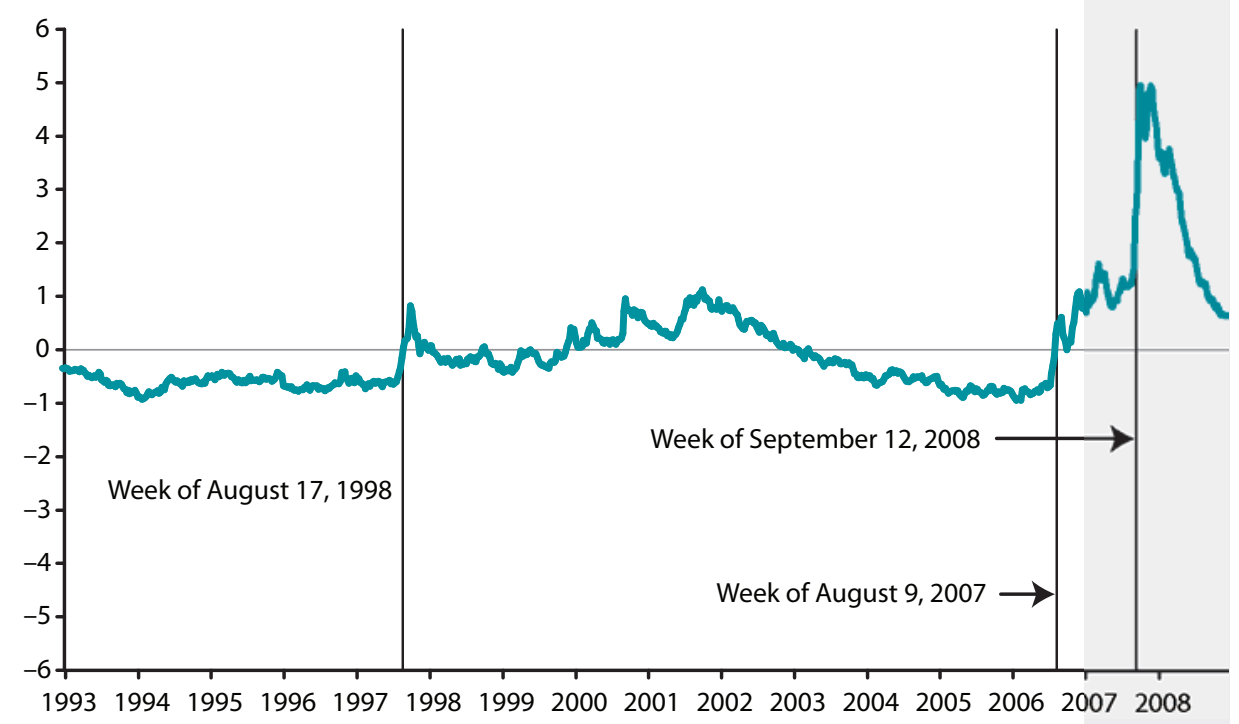

\section{See detailed view below}

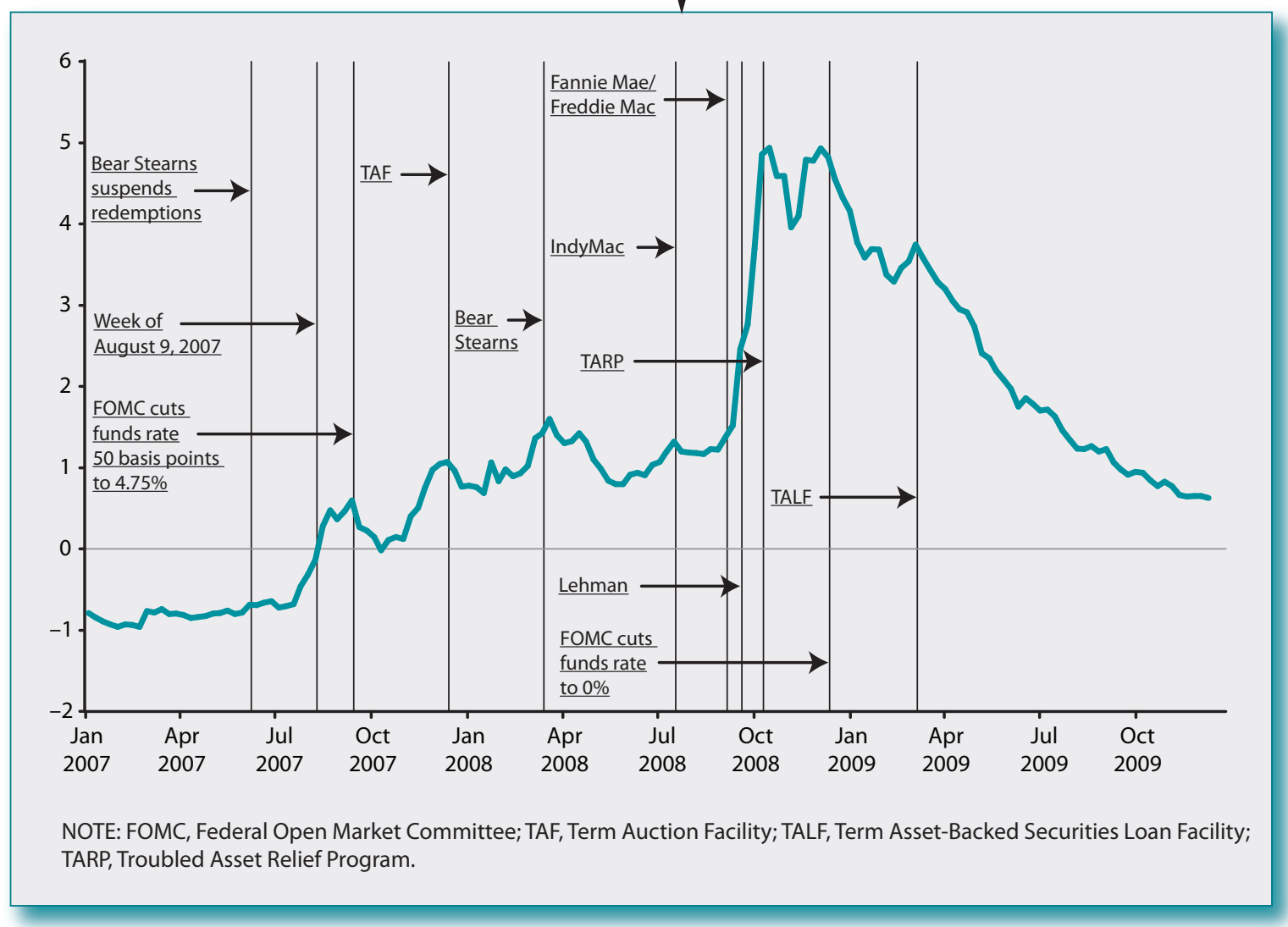

